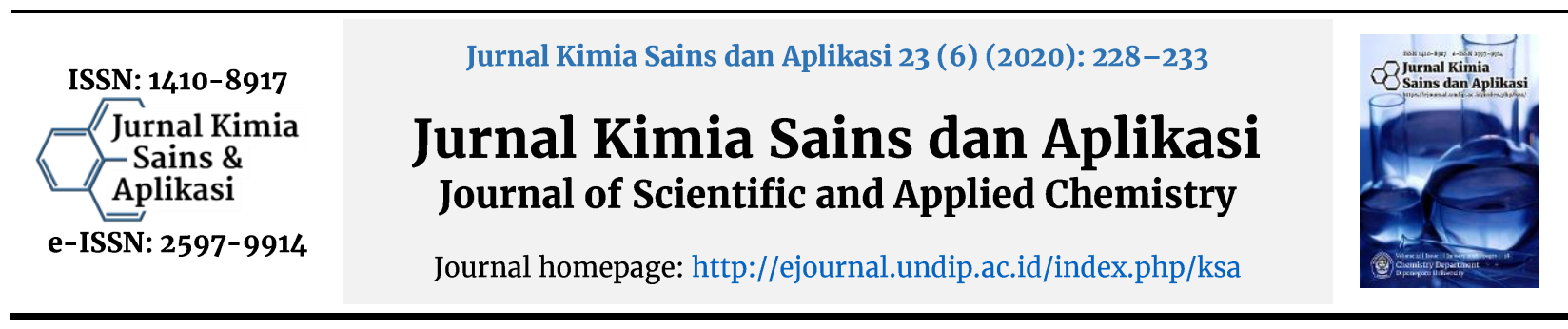

\title{
Synthesis and Characterization of Pyrazine Derived Compounds as Potential Materials for Hole Transporting Layer (HTL)
}

\author{
Vety Sri Harlinda Ayudha ${ }^{\mathrm{a},{ }^{*}}$, Mokhamat Ariefin ${ }^{\mathrm{a}}$ \\ a National Central University, Zhongli, Taoyuan, Taiwan \\ * Corresponding author: vetyayudha@gmail.com \\ https://doi.org/10.14710/jksa.23.6.228-233
}

\section{Article Info}

Article history:

Received: $27^{\text {th }}$ December 2019 Revised: $13^{\text {th }}$ May 2020 Accepted: $19^{\text {th }}$ May 2020 Online: $30^{\text {th }}$ June 2020

Keywords: pyrazine; hole transporting layer (HTL); energy gap

\begin{abstract}
Three simple compounds that have the potential as a hole transporting layer (HTL) based on pyrazine derivatives conjugated with electron donor groups in the form of triphenylamine have been successfully synthesized and characterized. The synthesis began with a substitution reaction at high temperatures between 4bromoaniline and 4-iodoanisole to produce 4-bromo- $N, N$-bis(methoxyphenyl)aniline, followed by substitution of bromo atoms with tributylstanum at low temperatures and inert atmosphere $\left(\mathrm{N}_{2}\right)$ producing 4-methoxy-N-(4(tributylstanyl)phenyl)aniline. The conjugation reaction was carried out through a Stille coupling reaction between 1,2-bis (4-bromophenyl)ethane-1,2-dione with 4-methoxy-N-(4-(tributylstanyl)phenyl) aniline at high temperatures with the aid of a $\mathrm{Pd}\left(\mathrm{PPh}_{3}\right)_{4}$ catalyst in an inert atmosphere $\left(\mathrm{N}_{2}\right)$. The reaction was continued with the imination reaction with 3 compounds, i.e., 1,2-diaminobenzene, 3,3diaminobenzidine and 2,3-diaminopiridin to produce three HTL compounds that were namely 4',4"-(quinoxaline-2,3-diyl)bis (N,N-bis(4(methoxyphenyl)-[1,1'biphenyl]-4-amine) (DNB), 4',4'",4'"' ',4'"',"' -([6,6' -biquinoxaline $]-2,2$ ',3,3'tetrayl) tetrakis(N,N-bis(4-methoxyphenyl)-[1,1'-biphenyl]-4-amine) (bDNB), and 4',4"'-(pyrido[2,3-b]pyrazine-2,3-diyl)bis(N,N-bis (4-methoxyphenyl)[1,1'-biphenyl]-4-amine) (DNP). The optical and electrochemical properties of DNB, bDNB, and DNP were analyzed by UV-Vis and Differential Pulse Voltammetry (DPV). The optical and electrochemical properties show the energy levels of the HOMO and LUMO of the three compounds. Hence their potential can be estimated as HTL compounds. The three compounds show $\lambda_{\max }$ of $348 \mathrm{~nm}, 356 \mathrm{~nm}$, and 350 nm for DNB, bDNB, and DNP. Based on DPV results, the HOMO values for DNB, bDNB, and DNP are $-5.03 \mathrm{eV},-5.02 \mathrm{eV}$, and $-4.98 \mathrm{eV}$ and LUMO values of $-2.46 \mathrm{eV}$, $-2.76 \mathrm{eV}$ and $-2.87 \mathrm{eV}$, respectively. The three compounds' thermal properties were analyzed using TGA, with the results showing that the three compounds had good thermal resistance with a decomposition point above $400^{\circ} \mathrm{C}$. Based on optical, electrochemical, and thermal analysis, DNB and bDNB have almost the same properties. Thus, it is expected that the three compounds have the potential as HTL material, with DNB and bDNB better than DNP.
\end{abstract}

\section{Introduction}

The development of electronic technology has been developing quickly; this is followed by the increasing need for electricity usage. Coal is still the primary energy source used in electricity generation. However, the use of coal causes many losses, such as environmental pollution, air pollution [1], or even respiratory disorders [2].
Based on these problems, we need a renewable electricity source that is more environmentally friendly such as hydroelectric energy [3], geothermal electric energy [4], or solar electric energy (solar panels). From several renewable energy sources, solar panels are promising renewable sources because of their unlimited sources. However, the use of solar panels as an energy source still has its challenges in its application, such as 
expensive materials or low energy conversion. Based on data compiled by the National Renewable Energy Laboratory (NREL), solar panels made from Si-active crystals still hold the highest conversion efficiency, compared to solar panels with other active ingredients, such as organic solar panels, or perovskite. To that end, researchers in the field of materials to date have tried to find ways to optimize the value of power conversion energy (PCE) from solar panels, both research in the manufacture of devices (devices) or the synthesis of potential compounds for solar panels [5].

Several solar panels have evolved, such as organic photovoltaic (OPV) with active ingredients in the form of small organic compounds or polymers, Si-crystalline, and Perovskite Solar Cells (PSC). Perovskite is a calcium titanium oxide $\left(\mathrm{CaTiO}_{3}\right)$ mineral that was discovered by Gustave Rose in 1839. In perovskite solar panels, the term perovskite used does not refer to $\mathrm{CaTiO}_{3}$ crystals, but crystalline compounds that have the same structure as $\mathrm{CaTiO}_{3}$ [6]. During its development, one of the perovskites used in solar cells was methylammonium lead halide $\left(\mathrm{CH}_{3} \mathrm{NH}_{3} \mathrm{PbI}\left(\mathrm{I}_{3}\right)\right)$ developed by Miyasaka. $\mathrm{CH}_{3} \mathrm{NH}_{3} \mathrm{PbI}\left(\mathrm{I}_{3}\right)$ as an active component in solar cells has advantages such as low exciton binding energy, sharp optical absorption, and good carrier diffusion-length [7].

PSC is composed of several essential parts, such as transparent conductive layers (IOP, indium tin oxide), the electron transporting layer (ETL), active layer (perovskite), the hole transporting layer (HTL), and metal electrodes. The composition of the PSC can be seen in Figure 1(i). HTL is a part that functions to transfer holes (positive charges) to the electrodes. Generally, this section uses Spiro-OMeTAD (Figure 1 (ii)) as its forming material. However, Spiro-OMeTAD is a compound that is difficult to synthesize and purify, so we need a new compound that is easier to make and has a high PCE when used in PSC [8].

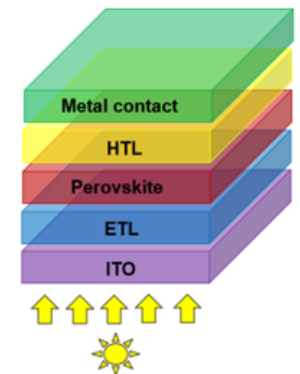

(i)

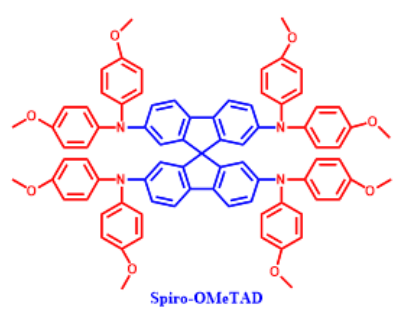

(ii)
Figure 1. (i) PSC composition; (ii) Spiro-OMeTAD structure

Liu et al. [9] succeeded in making a simple HTL based on carbazole derivatives with three electron-rich groups in the form of triphenylamine, named LD22 with $\lambda_{\max }$ of $381 \mathrm{~nm}$. LD22 has HOMO and LUMO of $-5.27 \mathrm{eV}$ and $-2.30 \mathrm{eV}$, respectively, while Spiro-OMeTAD $\left(\lambda_{\max }=\right.$ $386 \mathrm{~nm}$ ) with the same measurement method, has HOMO and LUMO values of $-5.14 \mathrm{eV}$ and $-2.15 \mathrm{eV}$. LD22 achieved PCE up to $13 \%$ when applied to the PSC, while Spiro-OmeTAD produced PCE $\mathbf{1 7 . 1 8} \%$ when applied to the same device. Cui et al. [10] could also synthesize simple HTL compounds from hexaphenylbenzene (HPB) derivatives with the donor group triphenylamine. HPB has HOMO and LUMO values of $-5.20 \mathrm{eV}$ and $-2.10 \mathrm{eV}$ with $\lambda_{\max }$ of $367 \mathrm{~nm}$ and can reach PCE up to $12.9 \%$. Based on this, then, in this study, developed an organic material based on pyrazine derivatives with an electron donor group triphenylamine, which can be used as HTL.
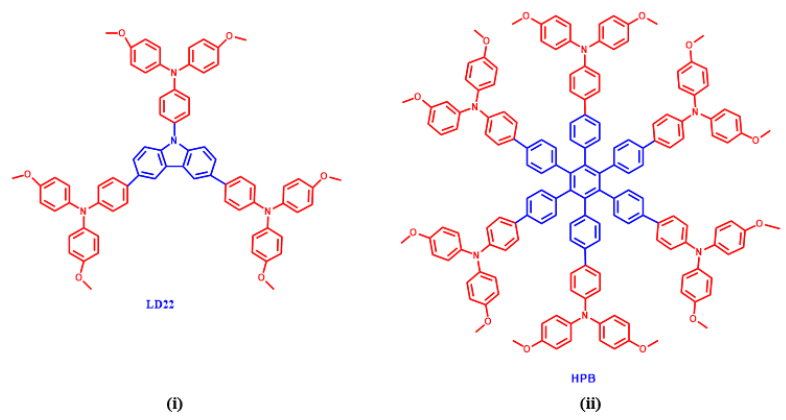

Figure 2. (i) LD22 structure; (ii) HPB structure

\section{Methodology}

The synthesis of 4',4"-(kuinoksalin-2,3diil)bis(N,N-bis(4(metoksifenil)-[1,1' - bifenil]-4amine) (DNB), 4',4'"',4'"',,4','”'"-([6,6'biquinoxaline]-2,2',3,3'-tetrayl) tetrakis(N,N-bis(4methoxyphenyl)-[1,1'-biphenyl]-4-amine) (bDNB), and 4',4"'-(pyridine[2,3-b]pyrazine-2,3-diyl)bis(N,Nbis(4-methoxyphenyl)-[1,1'-biphenyl]-4-amine)

(DNP) started from synthesis 4-bromo-N,N-bis (4methoxyphenyl)aniline (a) using starting material 4bromoanilin (i) and 4-iodoanisole (j) (step i). In stage ii, the transformation of $\mathrm{Br}$ group to tributyltin chloride was carried out through a substitution reaction between compound (a) and tributyltin chloride (d) to produce 4methoxy-N-(4-(tributylstanyl)phenyl)aniline Furthermore, the Stille coupling reaction (step iii) was carried out between compound (b) and 1,2-bis (4bromophenyl)ethane-1,2-dione (e) so that the compound 1,2-bis(4'-bis(4-methoxyphenyl)amino)[1.1'-biphenyl]-4-il)ethane-1,2-dion (c) was obtained. From these compounds, an imitation was carried out using 1,2-diaminobenzidine (f), 2,3-diaminopiridin (g), and 3,3'-diaminobenzidine (h) to obtain the desired HTL. The complete scheme can be seen in Figure 3.

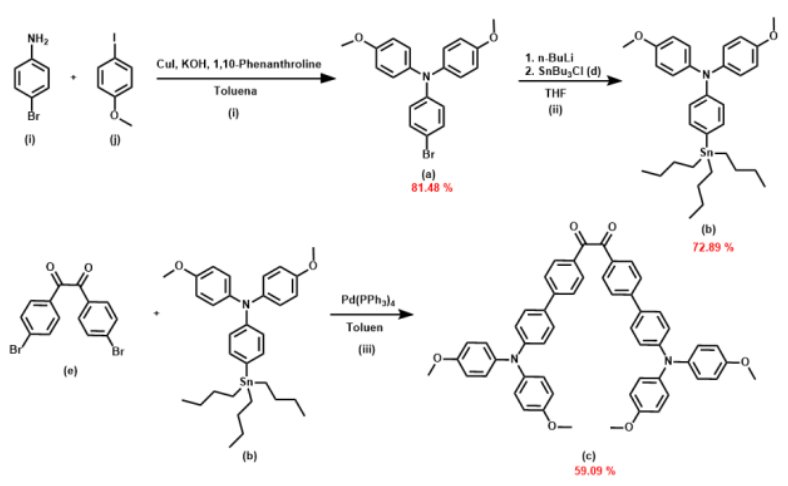




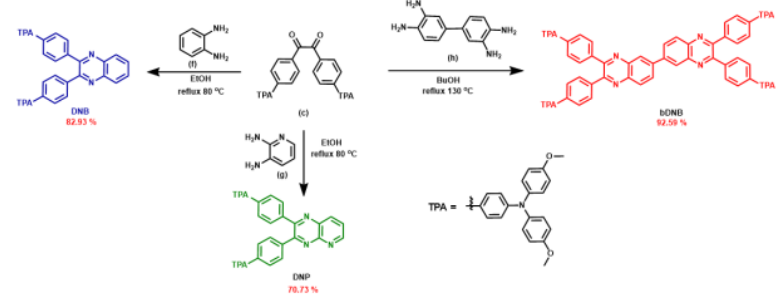

Figure 3. Synthesis of DNB, bDNB, and DNP

\subsection{Equipment and Materials}

The materials used in the experiment included 4bromoaniline, 1-iodo-4-methoxybenzene, dry toluene, 2.5 M n-butyl lithium, tributyltin chloride, dry tetrahydrofuran (THF), 4,4'-dibromobenzil, tetrakis (triphenylphosphine) palladium $\left(\mathrm{Pd}\left(\mathrm{PPh}_{3}\right) 4\right), 1,2-$ diaminobenzidine, 2,3-diaminopiridin, 3,3'diaminobenzidine, ethanol, n-butanol, chloroform- $d$, ethyl acetate, dichloromethane (DCM), and n-hexane. For compound characterization, ${ }^{1} \mathrm{H}-\mathrm{NMR}$ and ${ }^{13} \mathrm{C}-\mathrm{NMR}$ Bruker Model $300 \mathrm{~Hz}$ and $500 \mathrm{~Hz}$, Hitachi UV-Vis spectrophotometer, Differential pulse voltammetry (DPV) with Pt and $\mathrm{Ag} / \mathrm{AgCl}$ electrodes, and Perkin Elmer TGA-7 were used

\subsection{Synthesis of 4-bromo-N,N-bis(4- methoxyphenyl)aniline (a)}

4-bromoaniline (10 g, $58.13 \mathrm{mmol}$ ), 1-iodo-4methoxybenzene $(35.52 \mathrm{~g}, 14.53 \mathrm{mmol})$, CuI (0.554 g, $2.91 \mathrm{mmol}), \mathrm{KOH}(25.44 \mathrm{~g}, 45.34 \mathrm{mmol})$, 1,10-phenanthroline $(0.419 \mathrm{~g}, 2.33 \mathrm{mmol})$ were put into $250 \mathrm{~mL}$ of a round bottom flask which has been conditioned on $\mathrm{N}_{2}$ atmosphere. Then in the mixture, 60 $\mathrm{mL}$ of dried toluene was added. The mixture was stirred and refluxed for 24 hours at $120^{\circ} \mathrm{C}$. After that, some methanol was added to the mixture, and all the solvents were evaporated. The result of the evaporation was extracted using dichloromethane (DCM) and water. The product was purified using column chromatography with hexane: ethyl acetate $(49: 1)$ eluent to obtain compound a (16.5 g, 81.84\%) as a white solid. ${ }^{1} \mathrm{H}$ NMR $\left(500 \mathrm{MHz}, \mathrm{CDCl}_{3}\right): \delta 7.232 \mathrm{ppm}(\mathrm{d}, 2 \mathrm{H}, \mathrm{J}=8.50), \delta 7.023$ $\operatorname{ppm}(\mathrm{d}, 4 \mathrm{H}, \mathrm{J}=9.00), \delta 6.820 \mathrm{ppm}(\mathrm{d}, 4 \mathrm{H}, \mathrm{J}=9.00), \delta$ $6.787 \mathrm{ppm}(\mathrm{d}, 2 \mathrm{H}, \mathrm{J}=8.50), \delta 3.790 \mathrm{ppm}(\mathrm{s}, 6 \mathrm{H})$.

\subsection{Synthesis of 4-methoxy-N-(4-methoxyphenyl)-} N-(4- (tributylstanil)phenyl)aniline (b)

Compound a $(2.01 \mathrm{~g}, 5.78 \mathrm{mmol})$ was put into a 100 $\mathrm{mL}$ round bottom flask conditioned in $\mathrm{N}_{2}$ atmosphere, then dissolved using $40 \mathrm{~mL}$ dry THF. After that, $2.5 \mathrm{M} \mathrm{n-}$ butyllithium $(2.5 \mathrm{~mL}, 6.36 \mathrm{mmol}$ ) was added to the solution of the compound a slowly, at $-78^{\circ} \mathrm{C}$ and stirred for 2 hours (maintaining temperature). After 2 hours, $\mathrm{Bu}_{3} \mathrm{SnCl}(1.74 \mathrm{~mL}, 6.35 \mathrm{mmol})$ was added at $-78^{\circ} \mathrm{C}$, and the temperature was allowed to rise slowly until it reached room temperature and left overnight. After overnight, the $\mathrm{NaCl}$ solution was added to the mixture and extracted using diethyl ether/water. The organic layer obtained was dried using anhydrous sodium sulfate and evaporated. The crude was purified by distillation to obtain compound b (2.5 g, yield $72.89 \%)$ as a yellow liquid. ${ }^{1} \mathrm{H} \mathrm{NMR}\left(500 \mathrm{MHz}, \mathrm{CDCl}_{3}\right): \delta 7.229 \mathrm{ppm}(\mathrm{d}, 2 \mathrm{H}, \mathrm{J}$ $=8.00), \delta 7.057 \mathrm{ppm}(\mathrm{d}, 4 \mathrm{H}, \mathrm{J}=8.50), \delta 6.886 \mathrm{ppm}(\mathrm{d}$, $2 \mathrm{H}, \mathrm{J}=8.00), \delta 6.817 \mathrm{ppm}(\mathrm{d}, 4 \mathrm{H}, \mathrm{J}=9.00), \delta 3.789 \mathrm{ppm}$ (s, 6H).

\subsection{Synthesis of 1,2-bis(4'-bis(4- methoxyphenyl)amino)-[1,1' -biphenyl]-4- il)ethane-1,2-dion (c)}

Compounds b (1.29 g, $2.17 \mathrm{mmol}), \mathrm{Pd}\left(\mathrm{PPh}_{3}\right) 4(63$ $\mathrm{mg}, 0.055 \mathrm{mmol}$ ), and 1,2-bis(4-bromophenyl)ethane1,2-dione (200 mg, $0.54 \mathrm{mmol}$ ) were put into a $100 \mathrm{~mL}$ round bottom flask which had been conditioned in $\mathrm{N}_{2}$ atmosphere. Then, it was dissolved using $30 \mathrm{~mL}$ dry toluene. The solution was refluxed for 48 hours. After that, the reaction mixture was filtered using celite and washed with ethyl acetate. Then, all the solvents were evaporated. The evaporation results were purified using column chromatography with eluents of hexane: ethyl acetate $(4: 1)$ to obtain compound c $(260 \mathrm{mg}, 59.09 \%$ yield) as an orange solid. ${ }^{1} \mathrm{H} \mathrm{NMR}\left(500 \mathrm{MHz}, \mathrm{CDCl}_{3}\right): \delta$ 8.009 ppm (d, $2 \mathrm{H}, \mathrm{J}=8.50), \delta 7.672 \mathrm{ppm}(\mathrm{d}, 2 \mathrm{H}, \mathrm{J}=8.50)$, $\delta 7.452 \mathrm{ppm}(\mathrm{d}, 2 \mathrm{H}, \mathrm{J}=9.00), \delta 7.101 \mathrm{ppm}(\mathrm{d}, 4 \mathrm{H}, \mathrm{J}=$ 8.50), $\delta 6.968(\mathrm{~d}, 2 \mathrm{H}, \mathrm{J}=8.50), \delta 6.857 \mathrm{ppm}(\mathrm{d}, 4 \mathrm{H}, \mathrm{J}=$ 8.50), $\delta 3.806 \mathrm{ppm}(\mathrm{s}, 6 \mathrm{H})$.

\subsection{Synthesis of DNB}

Compounds c (75 mg, $0.09 \mathrm{mmol})$ and 1,2diaminobenzene (11 $\mathrm{mg}, 0.101 \mathrm{mmol}$ ) were mixed into a $100 \mathrm{~mL}$ round bottom flask and dissolved in $30 \mathrm{~mL}$ ethanol. The mixture was refluxed for 24 hours. After that, the reaction mixture was filtered and the solids were washed using ethanol, so that a DNB (68 mg, $82.93 \%$ yield) was obtained as a yellow solids ${ }^{1} \mathrm{H}$ NMR $\left(500 \mathrm{MHz}, \mathrm{CDCl}_{3}\right): \delta 8.177 \mathrm{ppm}(\mathrm{dd}, 2 \mathrm{H}, \mathrm{J}=6.00), \delta 7.766$ $\operatorname{ppm}(\mathrm{dd}, 2 \mathrm{H}, \mathrm{J}=6.00), \delta 7.613 \mathrm{ppm}(\mathrm{d}, 4 \mathrm{H}, \mathrm{J}=8.50), \delta$ $7.545 \mathrm{ppm}(\mathrm{d}, 4 \mathrm{H}, \mathrm{J}=8.00), \delta 7.444(\mathrm{~d}, 4 \mathrm{H}, \mathrm{J}=8.50), \delta$ $7.083(\mathrm{~d}, 8 \mathrm{H}, \mathrm{J}=8.50), \delta 6.980(\mathrm{~d}, 4 \mathrm{H}, \mathrm{J}=8.50), \delta 6.842$ $\operatorname{ppm}(\mathrm{d}, 8 \mathrm{H}, \mathrm{J}=8.50), \delta 3.804 \mathrm{ppm}(\mathrm{s}, 12 \mathrm{H})$.

\subsection{Synthesis of bDNB}

Compounds c (55 mg, $0.07 \mathrm{mmol}$ ) and 3,3diaminobenzidine $(6.5 \mathrm{mg}, 0.03 \mathrm{mmol})$ were mixed into $100 \mathrm{~mL}$ round bottom flask and dissolved in $30 \mathrm{~mL}$ butanol. The mixture was refluxed for 24 hours. After that, the reaction mixture was filtered and the solid was washed using ethanol, so bDNB ( $50 \mathrm{mg}, 92.59 \%$ yield) was obtained in the form of orange solids. ${ }^{1} \mathrm{H}$ NMR (500 $\left.\mathrm{MHz}, \mathrm{CDCl}_{3}\right): \delta 8.593 \mathrm{ppm}(\mathrm{s}, 2 \mathrm{H}), \delta 8.310 \mathrm{ppm}(\mathrm{d}, 2 \mathrm{H}, \mathrm{J}$ $=9.00), \delta 8.232 \mathrm{ppm}(\mathrm{d}, 2 \mathrm{H}, \mathrm{J}=8.50), \delta 7.661 \mathrm{ppm}(\mathrm{d}$, $2 \mathrm{H}) 8 \mathrm{H}, \mathrm{J}=7.50), \delta 7.572(\mathrm{~d}, 8 \mathrm{H}, \mathrm{J}=7.00), \delta 7,462(\mathrm{~d}, 8 \mathrm{H}$, $\mathrm{J}=8.50), \delta 7,091(\mathrm{~d}, 16 \mathrm{H}, \mathrm{J}=8.50), \delta 6,991(\mathrm{~d}, 8 \mathrm{H}, \mathrm{J}=$ 9.00), $\delta 6,848 \mathrm{ppm}(\mathrm{d}, 16 \mathrm{H}, \mathrm{J}=9.00), \delta 3.808 \mathrm{ppm}(\mathrm{s}$, 24H).

\subsection{Synthesis of DNP}

Compounds c (75 mg, $0.09 \mathrm{mmol}$ ) and 2,3diaminopiridin ( $11 \mathrm{mg}, 0.101 \mathrm{mmol}$ ) were mixed into 100 $\mathrm{mL}$ round bottom flask and dissolved in $30 \mathrm{~mL}$ ethanol. The mixture was refluxed for 24 hours. After that, the reaction mixture was filtered, and the solid was washed using methanol. Then the crude was purified by column chromatography with hexane: ethyl acetate (2: 1) eluent 
to obtain DNP (58 mg, $70.73 \%$ yield) in the form of orange solids. ${ }^{1} \mathrm{H} \mathrm{NMR}\left(500 \mathrm{MHz}, \mathrm{CDCl}_{3}\right): \delta 9.156 \mathrm{ppm}(\mathrm{s}$, $1 \mathrm{H}), \delta 8.518 \mathrm{ppm}(\mathrm{d}, 1 \mathrm{H}, \mathrm{J}=7.00), \delta 7.733 \mathrm{ppm}(\mathrm{m}, 3 \mathrm{H}), \delta$ $7.643 \mathrm{ppm}(\mathrm{m}, 2 \mathrm{H}), \delta 7.570(\mathrm{~d}, 4 \mathrm{H}, \mathrm{J}=9.00), \delta 7.457 \mathrm{ppm}$ (b, 4H), $\delta 7.077 \mathrm{ppm}(\mathrm{b}, 8 \mathrm{H}), \delta 6.842 \mathrm{ppm}(\mathrm{d}, 4 \mathrm{H}, \mathrm{J}=$ $8.50), \delta 6.845 \mathrm{ppm}(\mathrm{d}, 8 \mathrm{H}, \mathrm{J}=8.00), \delta 3.804 \mathrm{ppm}(\mathrm{s}, 12 \mathrm{H})$.

\subsection{NMR analysis}

NMR is a qualitative analysis method for determining the chemical structure of a compound. In this study, ${ }^{1} \mathrm{H}-\mathrm{NMR}$ was used, spectra were recorded with $300 \mathrm{MHz}$ Bruker and $500 \mathrm{MHz}$ using $\mathrm{CDCl}_{3}$ solvent.

\subsection{Ultraviolet-visible (UV-Vis) analysis}

All final compounds were analyzed using a UV-Vis spectrophotometer. 0 -dichlorobenzene was used as a solvent and a blank solution. The cuvette used was made of orz with a thickness of $10 \mathrm{~mm}$. The results of the UV analysis were used to calculate the energy gap (Eg) with the formula:

$$
E_{g}=\frac{1243}{\lambda_{\text {onset }}} \mathrm{eV}
$$

\subsection{Differential Pulse Voltammetry (DPV) Analysis}

Differential Pulse Voltammetry (DPV) analysis is used to determine the HOMO-LUMO level of the final compound. O-dichlorobenzene was used as a solvent. DPV was measured in an inert condition $\left(\mathrm{N}_{2}\right)$ and was used ferrocene as an internal standard in measurement.

\section{Results and Discussion}

\subsection{Optical properties}

The results of the UV-Vis analysis of DNB, bDNB, and DNP compounds are presented in Figure 4. Based on these spectra results, the values of $\lambda_{\max }$ for DNB, bDNB, and DNP are $348.5 \mathrm{~nm}, 356 \mathrm{~nm}$, and $350 \mathrm{~nm}$. In the bDNB compound, the absorption peak produced was not significantly different even though it was more conjugated than the other two compounds. This can be explained because, in bDNB compounds, the bond between $\mathrm{C}$ atoms in one benzene ring and $\mathrm{C}$ in another benzene rotates (there is a dihedral angle), so the conjugation of bDNB becomes imperfect [11]. This gives an effect on the value of $\lambda_{\max }$ obtained. Based on these data, the three compounds have $\lambda_{\max }$ below $400 \mathrm{~nm}$, as well as the Spiro-OMeTAD uptake $\left(\lambda_{\max }=386 \mathrm{~nm}\right)$ [9], so that the absorption does not overlap with the absorption of perovskite. The existence of additional peaks that overlap with the perovskite absorption often leads to reduced photocurrent in the solar panel, thus disrupting the efficiency of the solar panel [12].

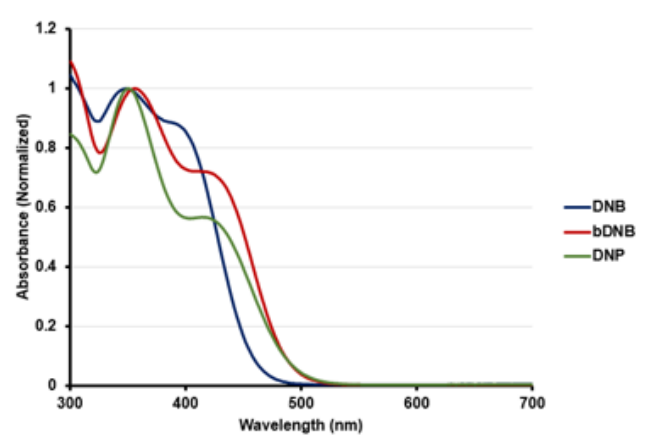

(a)

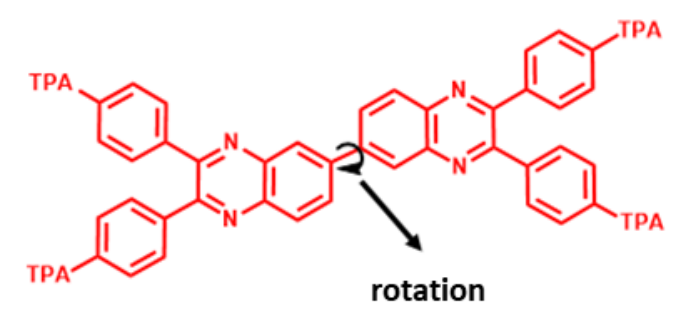

(b)

Figure 4. (a) UV-Vis spectra of DNB, bDNB, and DNP; (b) Rotation on bDNB

The energy gap $\left(E_{g}\right)$ values of DNB, bDNB, and DNP from optical calculations are $2.65 \mathrm{eV}, 2.5 \mathrm{eV}$, and $2.49 \mathrm{eV}$. $\mathrm{E}_{\mathrm{g}}$ of DNB is higher when compared to DNP because N atom is more electronegative than $\mathrm{C}$ atom (on the benzene DNB ring), so $\mathrm{N}$ atom can decrease the LUMO level of DNP. The optical properties of the three compounds are summarized in Table 1.

Table 1. Optical properties of DNB, bDNB, and DNP

\begin{tabular}{cccc}
\hline Compound & $\lambda_{\max }(\mathrm{nm})$ & $\lambda_{\text {onset }}(\mathrm{nm})$ & $\mathrm{E}_{\text {gap }}(\mathrm{eV})$ \\
\hline DNB & 348 & 467 & 2.65 \\
bDNB & 356 & 496.5 & 2.50 \\
DNP & 350 & 497.5 & 2.49 \\
\hline
\end{tabular}

\subsection{Electrochemical properties}

DPV analysis is used to obtain the reduction potential and oxidation potential of DNB, bDNB, and DNP, so the HOMO-LUMO value of each compound can be calculated. The values of HOMO, LUMO, reduction potential, oxidation potential, and $\mathrm{E}_{\mathrm{g}}$ of the three compounds are summarized in Table 2 . The LUMO values for the three compounds are $-2.46 \mathrm{eV},-2.76 \mathrm{eV}$, and $2.87 \mathrm{eV}$ for DNB, bDNB, and DNP. In DNB and bDNB compounds, different LUMO values are obtained, because bDNB has more electron-pushing groups than DNB, so the LUMO level of bDNB is more negative. The LUMO value on DNP is more negative when compared to the analogs, namely DNB. This more negative value is due to the presence of more electronegative $\mathrm{N}$ atoms in the pyridine ring. In contrast to LUMO, the HOMO values in the three compounds do not differ significantly. The overall energy level of HOMO-LUMO in the three compounds is illustrated using the diagram in Figure 5.

Spiro-OMeTAD is a commercial compound used as HTL material in general, having HOMO, LUMO, and Eg 
values of $-5.14 \mathrm{eV},-2.15 \mathrm{eV}$, and $2.99 \mathrm{eV}$, respectively [9]. For PSC applications, the HOMO value must be more positive than the HOMO value of perovskite (HOMO value $\mathrm{CH}_{3} \mathrm{NH}_{3} \mathrm{PbI}_{3}=-5.4 \mathrm{eV}$ ) [13], so that the hole more easily flow towards the electrode. In line with HOMO, the LUMO value from HTL must be more positive than the LUMO from perovskite (LUMO value $\mathrm{CH}_{3} \mathrm{NH}_{3} \mathrm{PbI}_{3}=-3.9$ $\mathrm{eV}$ [13], thus preventing electrons from flowing towards HTL. The three new HTL compounds that have been synthesized, both DNB, bDNB, and DNP, have HOMOLUMO characteristics that are not much different from Spiro-OMeTAD. Thus, it is expected that the three compounds can be applied as HTL in PSC.

Table 2. Electrochemical properties of DNB, bDNB, and DNP

\begin{tabular}{cccccc}
\hline Compound & $E_{\text {re }}(\mathrm{V})$ & $E_{\text {ox }}(\mathrm{V})$ & $\begin{array}{c}\text { LUMO } \\
(\mathrm{eV})\end{array}$ & $\begin{array}{c}\text { HOMO } \\
(\mathrm{eV})\end{array}$ & $\begin{array}{c}\text { Egap } \\
(\mathrm{eV})\end{array}$ \\
\hline DNB & -1.74 & 0.83 & -2.46 & -5.03 & 2.57 \\
bDNB & -1.44 & 0.82 & -2.76 & -5.02 & 2.26 \\
DNP & -1.33 & 0.78 & -2.87 & -4.98 & 2.10 \\
\hline
\end{tabular}
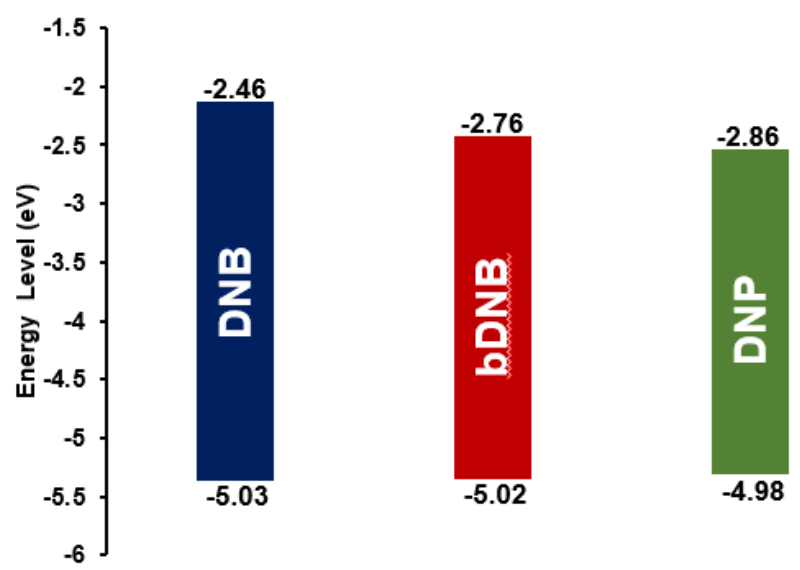

Figure 5. Energy level diagram of DNB, bDNB, and DNP

\subsection{Thermal properties}

Thermal properties were analyzed using Thermogravimetric analysis (TGA) to determine the heat resistance of the three final compounds synthesized. Besides TGA, the melting point apparatus is also used to determine the melting point of each compound. Based on the melting point apparatus results, the melting points for DNB, bDNB, and DNP were obtained respectively $254.3^{\circ} \mathrm{C}, 290.2^{\circ} \mathrm{C}$, and $257.5^{\circ} \mathrm{C}$. The melting point of the three compounds is higher than that of Spiro-OMeTAD (commercial HTL), which has a melting point of $240^{\circ} \mathrm{C}$. Based on the TGA results, a decomposition point ( $5 \%$ weight loss) from DNB, bDNB, and DNP were obtained at temperatures of $437.3^{\circ} \mathrm{C}, \quad 445.6^{\circ} \mathrm{C}$ and $400.9^{\circ} \mathrm{C}$ respectively, while Spiro-OMeTAD was at $424^{\circ} \mathrm{C}$ [14]. Based on these data, it is obtained that bDNB has the highest decomposition point. This is possible because bDNB has a higher molecular weight than the other two. From the TGA results, it can be concluded that the three compounds have good thermal stability to be used as HTL material.

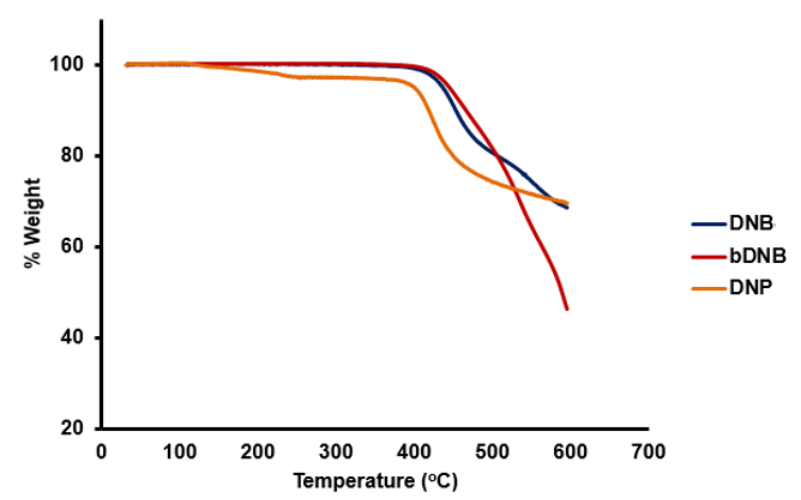

Figure 6. TGA graph of DNB, bDNB, and DNP

\section{Conclusions}

Three new pyrazine-based compounds, DNB, bDNB, and DNP have been successfully synthesized and characterized. Based on UV-Vis observations, the three compounds had $\lambda_{\max }$, each of $348.5 \mathrm{~nm}, 356 \mathrm{~nm}$, and 350 $\mathrm{nm}$ for DNB, bDNB, and DNP (while in commercial Spiro-OMeTAD, $\lambda_{\max }=386 \mathrm{~nm}$ ). Based on DPV results, the HOMO values for DNB, bDNB, and DNP are $-5.03 \mathrm{eV}$, $-5.02 \mathrm{eV}$, and $-4.98 \mathrm{eV}$, while the LUMO values are -2.46 $\mathrm{eV},-2.76 \mathrm{eV}$, and $-2.87 \mathrm{eV}$, respectively. The HOMOLUMO value of the three compounds is not much different from the HOMO-LUMO from Spiro-OMeTAD $($ HOMO $=-5.14 \mathrm{eV}, \mathrm{LUMO}=-2.14)$. The melting points for DNB, bDNB, and DNP are $254.3^{\circ} \mathrm{C}, 290.2^{\circ} \mathrm{C}$, and $257.5^{\circ} \mathrm{C}$ respectively, which is higher than that of SpiroOMeTAD $\left(240^{\circ} \mathrm{C}\right)$, with a decomposition point of $437.3^{\circ} \mathrm{C}$, $445.6^{\circ} \mathrm{C}$, and $400.9^{\circ} \mathrm{C}$. The decomposition point of the three compounds is above $400^{\circ} \mathrm{C}$, so it can be said that the three compounds have good thermal stability. With the appropriate optical, electrochemical, and thermal properties (almost the same as the commonly known HTL, Spiro-OMeTAD), it is expected that DNB, bDNB, and DNP have the potential to be applied as HTL on perovskite solar panels, with DNB and bDNB being better than with DNP.

\section{Acknowledgments}

We thank to National Central University of Taiwan for laboratory and instruments support.

\section{References}

[1] Sribas Goswami, Impact of coal mining on environment, European Researcher. Series A, 92, 3, (2015), 185-196

https://doi.org/10.13187/er.2015.92.185

[2] A. Scott Laney, David N. Weissman, Respiratory diseases caused by coal mine dust, Journal of occupational and environmental medicine/American College of Occupational and Environmental Medicine, $56,(2014)$, S18-S22

https://dx.doi.org/10.1097\%2FJOM.0000000000000260

[3] Mario T..L. Barros, Frank T. C. Tsai, Shu-li Yang, Joao E. G. Lopes, William W. G. Yeh, Optimization of large-scale hydropower system operations, Journal of Water Resources Planning and Management, 129, 3, (2003), 178-188

https://doi.org/10.1061/(ASCE)0733-9496(2003)129:3(178) 
[4] Nasruddin, M. Idrus Alhamid, Yunus Daud, Arief Surachman, Agus Sugiyono, H. B. Aditya, T. M. I. Mahlia, Potential of geothermal energy for electricity generation in Indonesia: A review, Renewable and Sustainable Energy Reviews, 53, (2016), 733-740 https://doi.org/10.1016/j.rser.2015.09.032

[5] Joel Jean, Patrick R. Brown, Robert L. Jaffe, Tonio Buonassisi, Vladimir Bulović, Pathways for solar photovoltaics, Energy \& Environmental Science, 8, 4, (2015), 1200-1219

https://doi.org/10.1039/C4EE04073B

[6] Osbel Almora, Lídice Vaillant-Roca, Germà GarciaBelmonte, Perovskite solar cells: a brief introduction and some remarks, Revista cubana de fisica, 34, 1, (2017), 58-68

[7] Akihiro Kojima, Kenjiro Teshima, Yasuo Shirai, Tsutomu Miyasaka, Organometal halide perovskites as visible-light sensitizers for photovoltaic cells, Journal of the American Chemical Society, 131, 17, (2009), 6050-6051

https://doi.org/10.1021/ja809598r

[8] Ajay Kumar Jena, Youhei Numata, Masashi Ikegami, Tsutomu Miyasaka, Role of spiro-OMeTAD in performance deterioration of perovskite solar cells at high temperature and reuse of the perovskite films to avoid $\mathrm{Pb}$-waste, Journal of Materials Chemistry A, 6, 5, (2018), 2219-2230 https://doi.org/10.1039/C7TA07674F

[9] Xuepeng Liu, Xiaoqiang Shi, Cheng Liu, Yingke Ren, Yunzhao Wu, Weng Yang, Ahmed Alsaedi, Tasawar Hayat, Fantai Kong, Xiaolong Liu, Yong Ding, Jianxi Yao, Songyuan Dai, A Simple CarbazoleTriphenylamine Hole Transport Material for Perovskite Solar Cells, The Journal of Physical Chemistry C, 122, 46, (2018), 26337-26343 https://doi.org/10.1021/acs.jpcc.8bo8168

[10] Bin-Bin Cui, Ying Han, Ning Yang, Shuangshuang Yang, Liuzhu Zhang, Yue Wang, Yifei Jia, Lin Zhao, Yu-Wu Zhong, Qi Chen, Propeller-Shaped, Triarylamine-Rich, and Dopant-Free HoleTransporting Materials for Efficient $n-i-p$ Perovskite Solar Cells, ACS Applied Materials \& Interfaces, 10, 48, (2018), 41592-41598 https://doi.org/10.1021/acsami.8b15423

[11] Young Soo Kwon, Jongchul Lim, Hui-Jun Yun, YunHi Kim, Taiho Park, A diketopyrrolopyrrolecontaining hole transporting conjugated polymer for use in efficient stable organic-inorganic hybrid solar cells based on a perovskite, Energy \& Environmental Science, 7, 4, (2014), 1454-1460 http://dx.doi.org/10.1039/C3EE44174A

[12] Frédéric Leroux, Atropisomerism, Biphenyls, and Fluorine: A Comparison of Rotational Barriers and Twist Angles, ChemBioChem, 5, 5, (2004), 644-649 https://doi.org/10.1002/cbic.200300906

[13] Chih-Hsin Chen, Yu-Ting Hsu, Bo-Cheng Wang, Chung-Lin Chung, Chih-Ping Chen, Thienoisoindigo-Based Dopant-Free Hole Transporting Material for Efficient $p-i-n$ Perovskite Solar Cells with the Grain Size in Micrometer Scale, The Journal of Physical Chemistry C, 123, 3, (2019), 1602-1609 https://doi.org/10.1021/acs.jpcc.8b10070
[14] Jagadish Salunke, Xing Guo, Zhenhua Lin, João R. Vale, Nuno R. Candeias, Mathias Nyman, Staffan Dahlström, Ronald Österbacka, Arri Priimagi, Jingjing Chang, Paola Vivo, Phenothiazine-Based Hole-Transporting Materials toward Eco-friendly Perovskite Solar Cells, ACS Applied Energy Materials, 2, 5, (2019), 3021-3027 https://doi.org/10.1021/acsaem.9bo0408 


\section{Supporting Information}

\section{NMR Spectra}

1.1. ${ }^{1} \mathrm{H}$ NMR (500 MHz) 4-bromo-N,N-bis(4-methoxyphenyl)aniline (a)

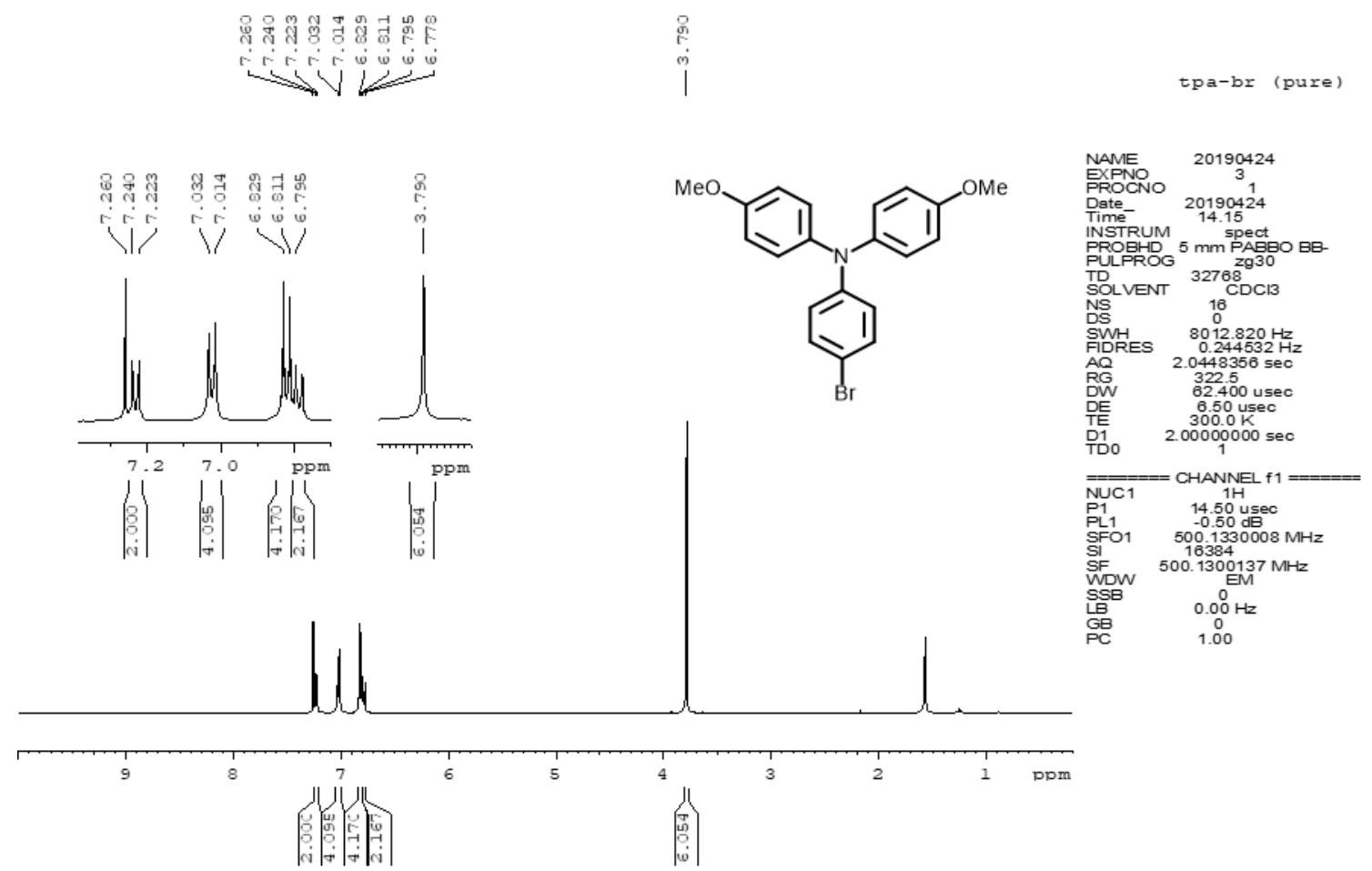

1.2. ${ }^{1} \mathrm{H}$ NMR (500 MHz) 4-metoksi- $\mathrm{N}$-(4-metoksifenil)-N-(4-(tributilstanil)fenil)anilin (b)

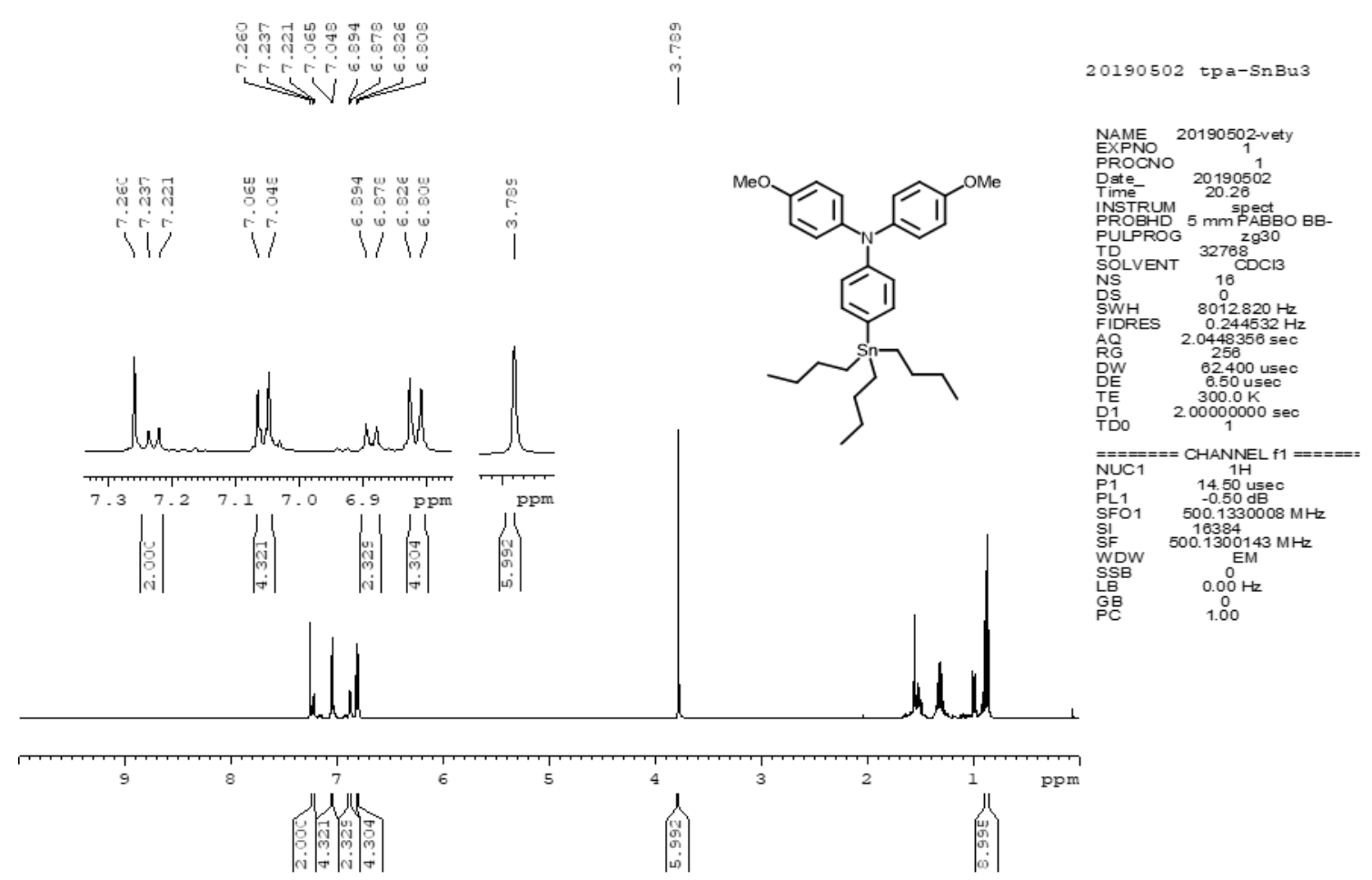


1.3. 'H NMR (500 MHz) 1,2-bis(4'-bis(4-methoxyphenyl)amino)-[1.1'-biphenyl]-4-il)ethane-1,2-dion (c)

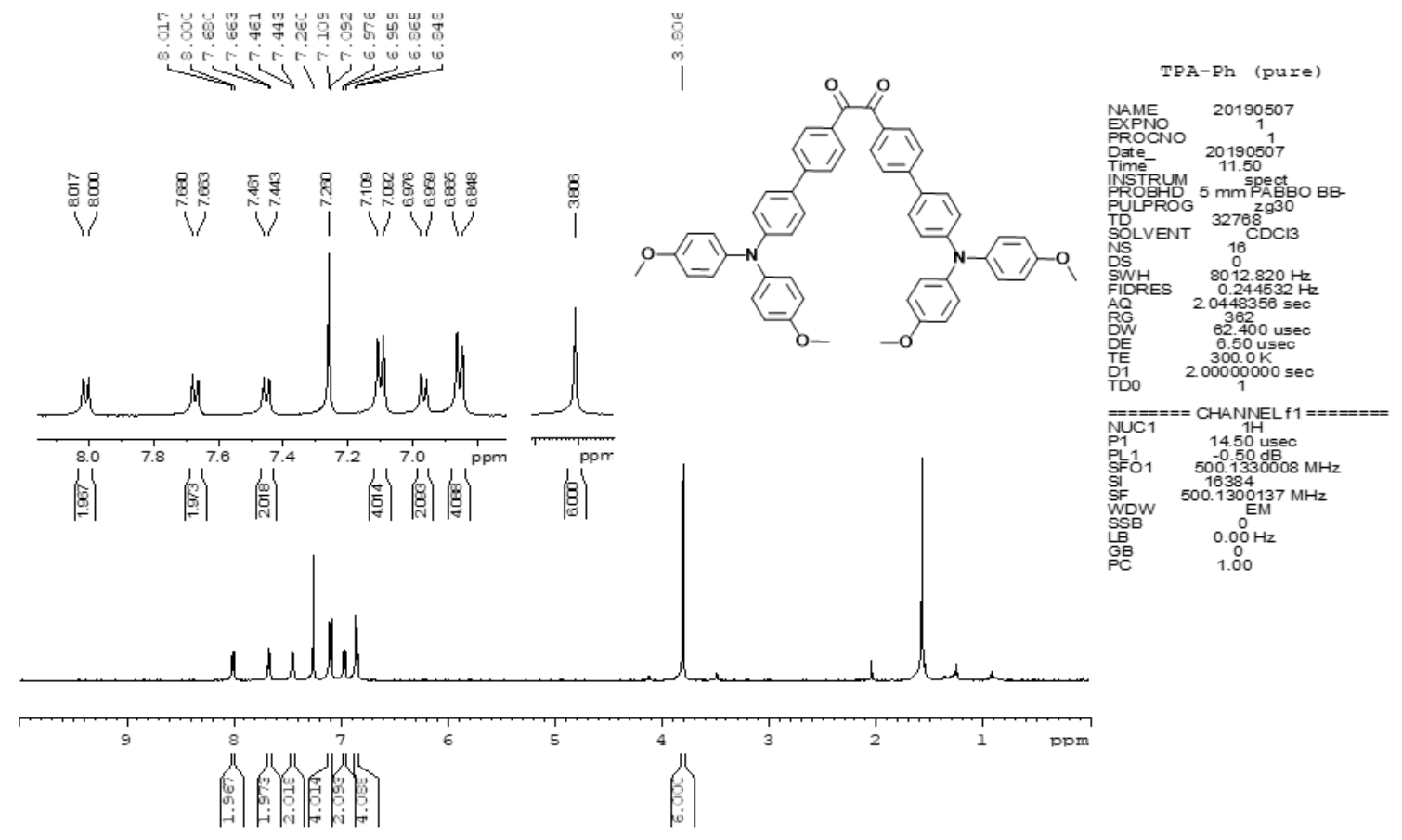

1.4. ${ }^{1} \mathrm{H}$ NMR (500 MHz) DNB

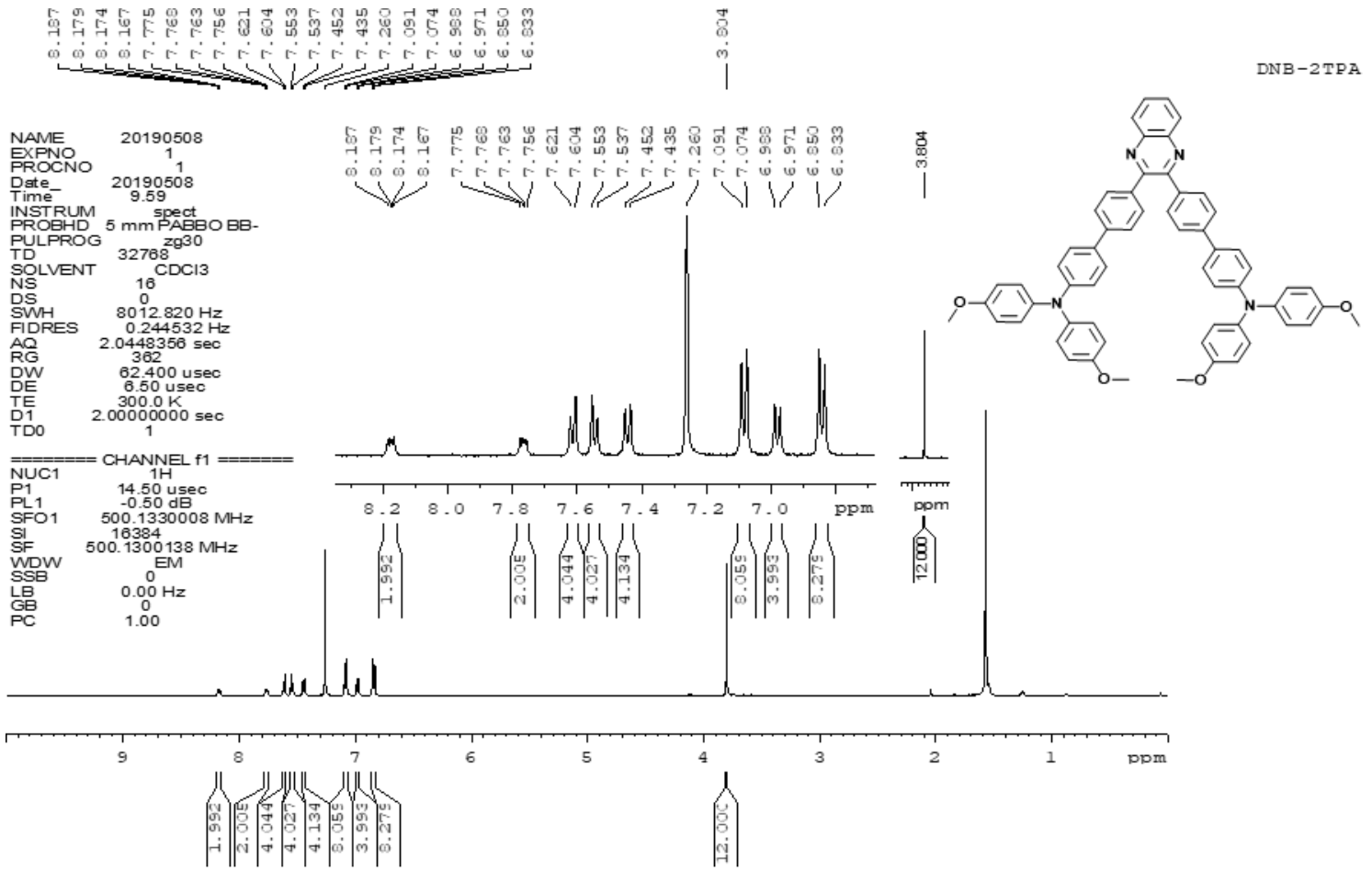


1.5. ${ }^{1} \mathrm{H}$ NMR (500 MHz) DNP

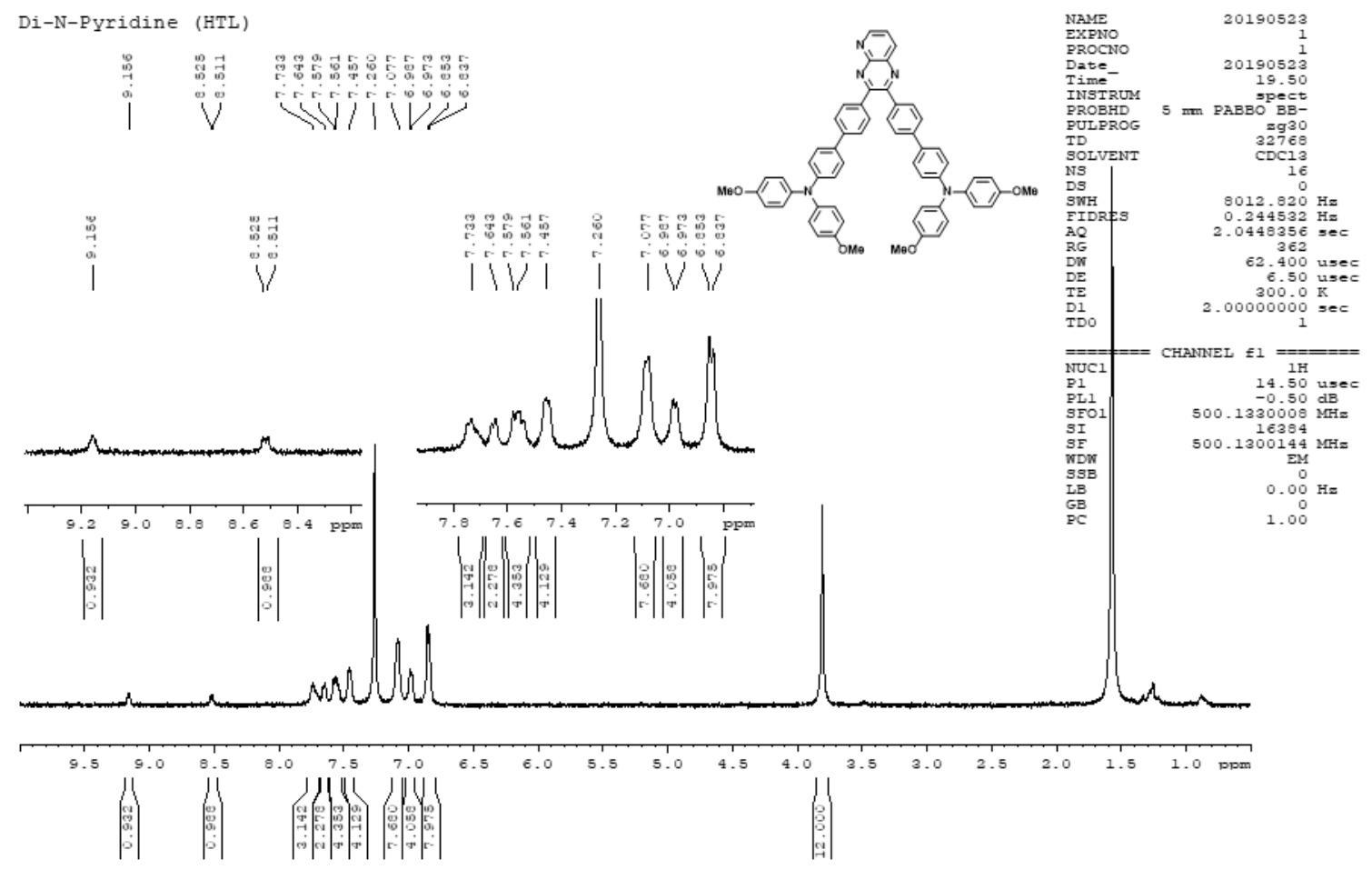

1.6. ${ }^{1} \mathrm{H}$ NMR ( $500 \mathrm{MHz}$ ) bDNB

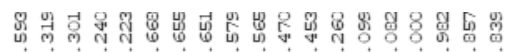

$\Leftrightarrow$
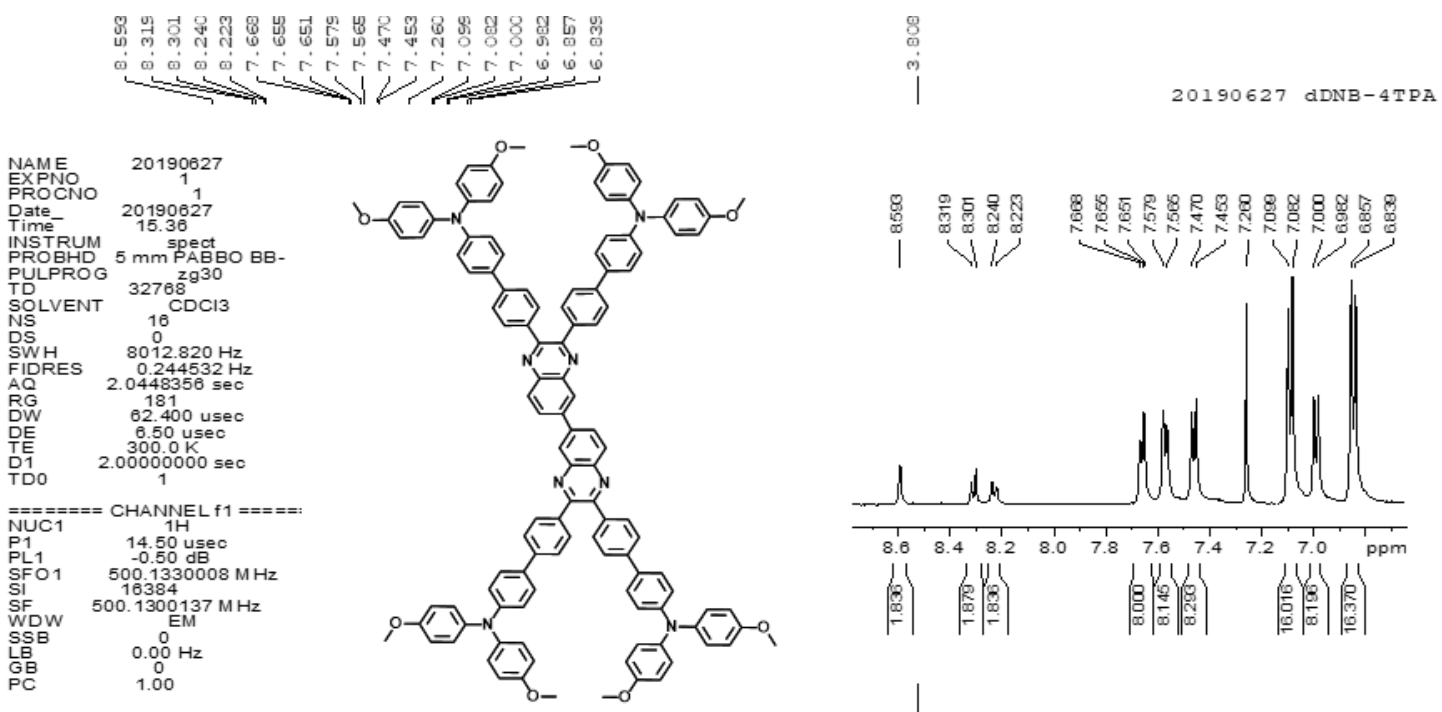

ard lal

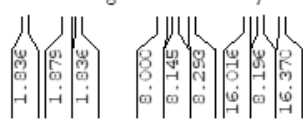

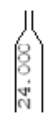


1.7. ${ }^{13} \mathrm{C}$ NMR ( $500 \mathrm{MHz}$ ) DNB

20190725 DNB-2TPA
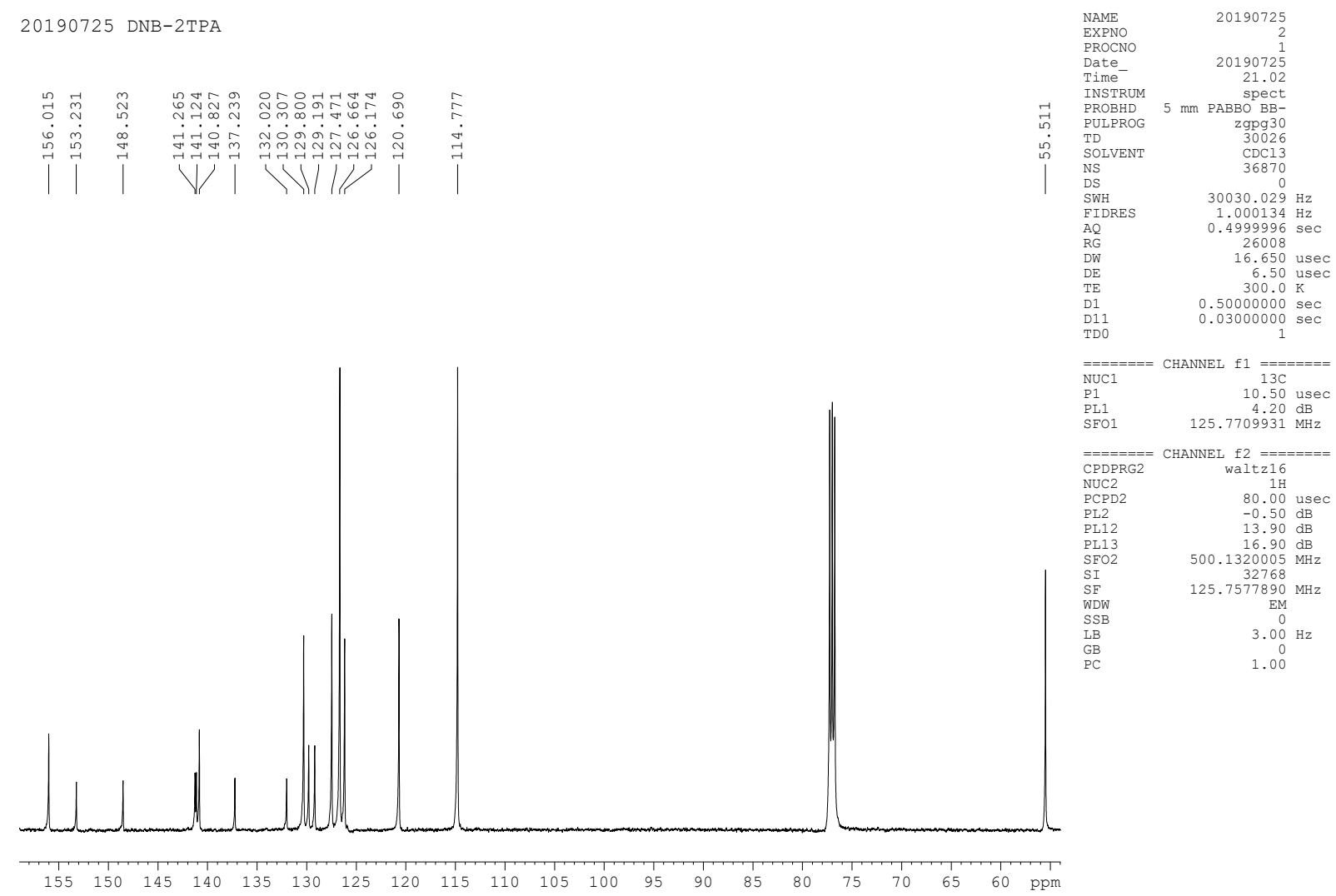

\section{8. ${ }^{13} \mathrm{C}$ NMR (500 MHz) bDNB}

20190625 bDNB-4TPA
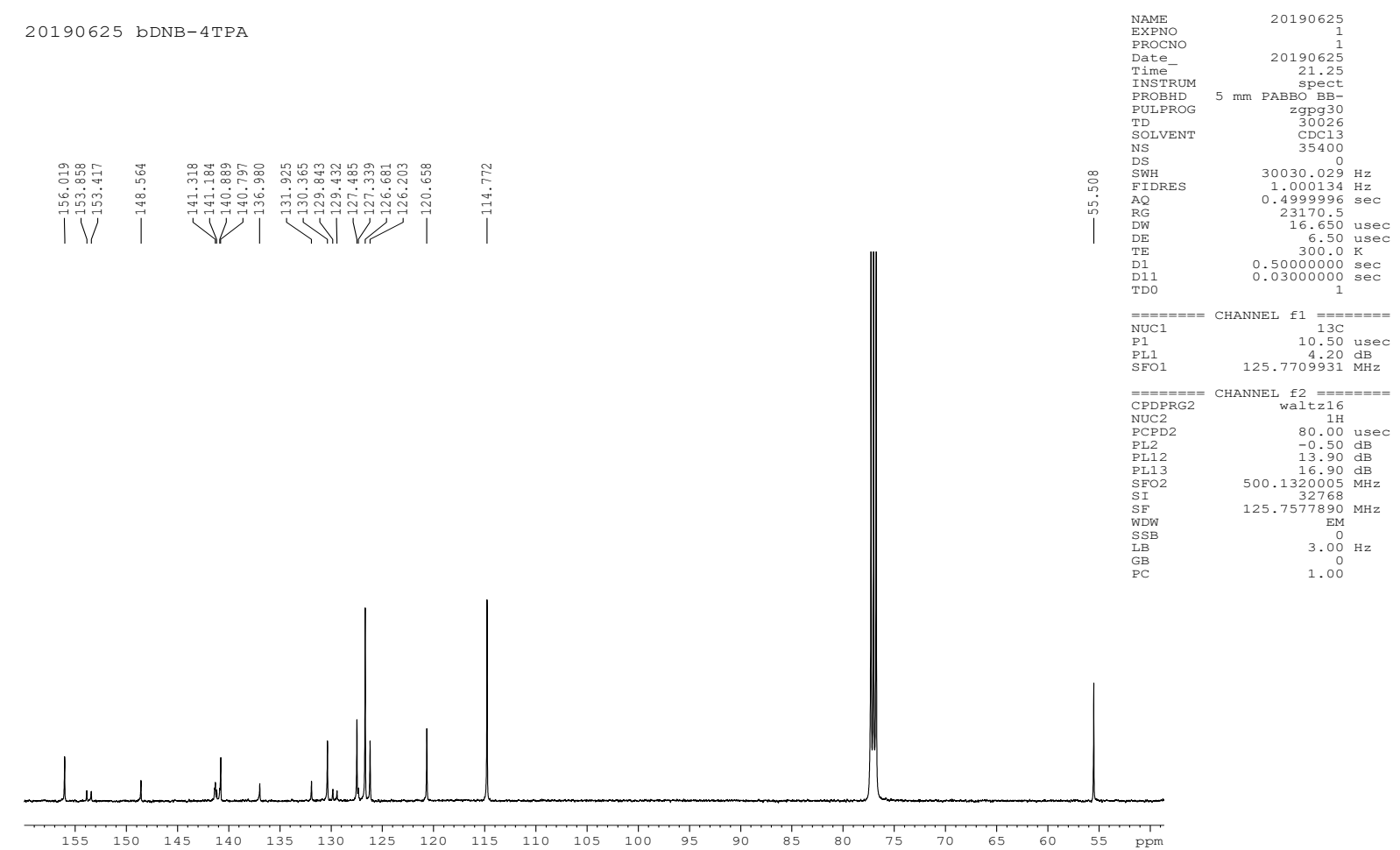
2. Mass Spectra (MS)

2.1. Mass Spectra of DNB (Exact Mass $=888.3676$ )

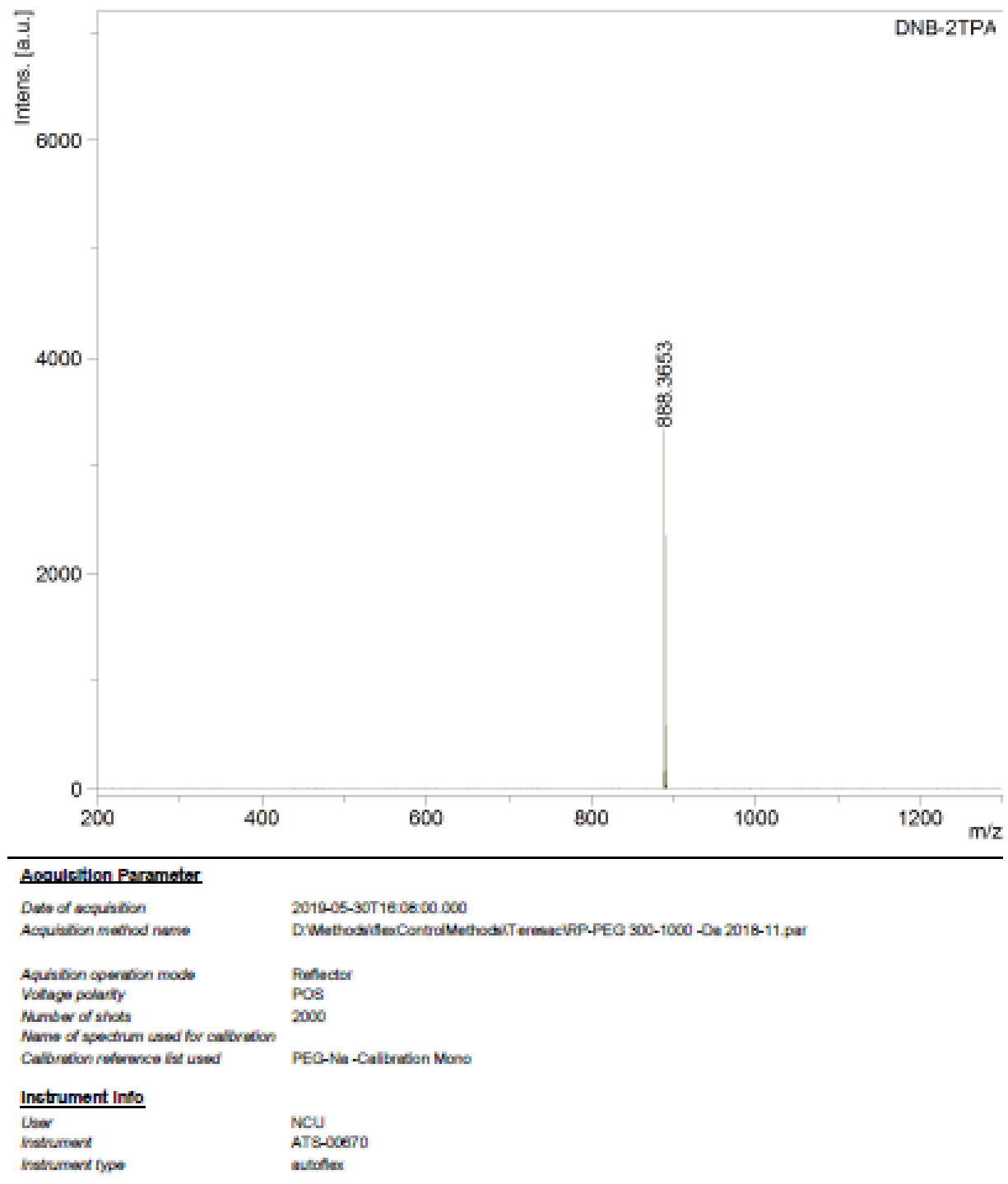


2.2. Mass Spectra of DNP (Exact Mass $=889.3628)$

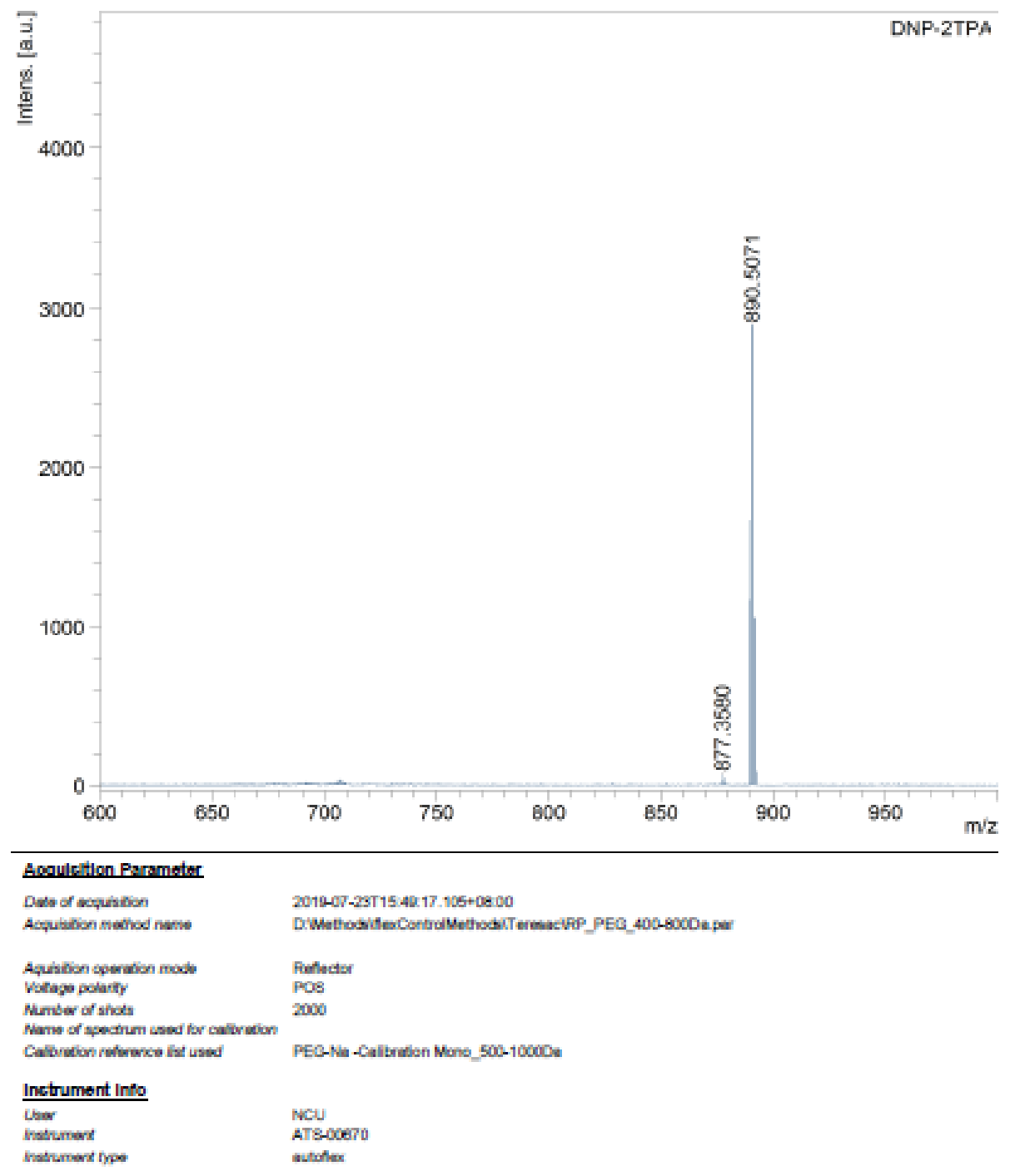


2.3. Mass Spectra of bDNB (Exact Mass $=1774.7195)$

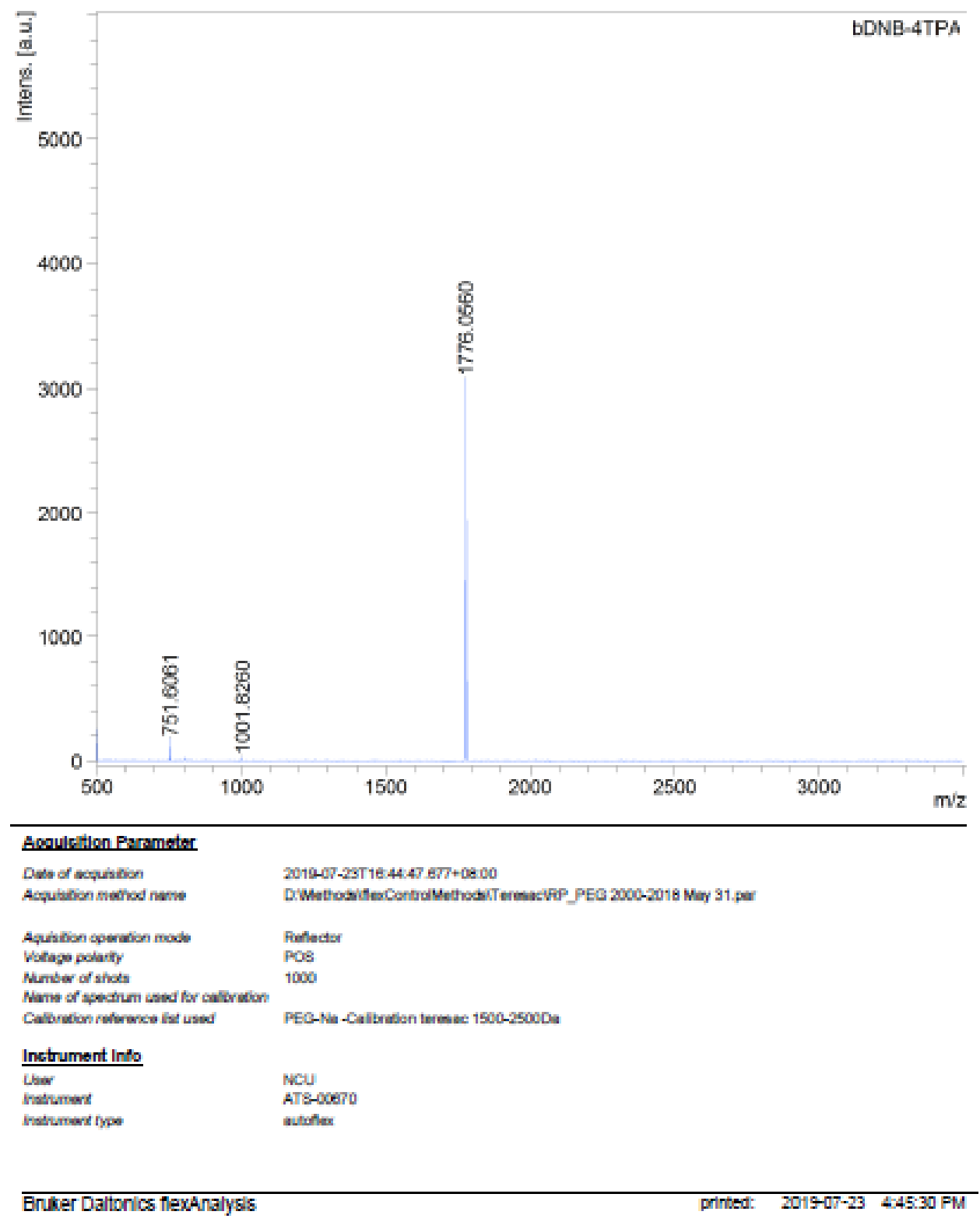

3. Optical, Thermal and Electrochemical Properties of Final Compounds

\begin{tabular}{|c|c|c|c|c|c|c|c|c|}
\hline \multirow{2}{*}{ Compound } & \multirow{2}{*}{$\begin{array}{l}\text { TGA } \\
\left({ }^{\circ} \mathrm{C}\right)^{\mathrm{a}}\end{array}$} & \multirow{2}{*}{$\begin{array}{c}\text { UV-Vis } \\
\lambda_{\max }(\mathrm{nm})\end{array}$} & \multicolumn{2}{|c|}{$E_{\text {gap }}(\mathrm{eV})$} & \multicolumn{4}{|c|}{$\mathrm{DPV}(\mathrm{eV})^{\mathrm{e}}$} \\
\hline & & & $\mathrm{DPV}^{\mathrm{c}}$ & UV-Vis ${ }^{\mathrm{d}}$ & Ere $(V)$ & $E_{o x}(V)$ & HOMO & LUMO \\
\hline DNB & 437.3 & 348 & 2.57 & 2.65 & -1.74 & 0.83 & -5.03 & -2.46 \\
\hline bDNB & 445.6 & 356 & 2.26 & 2.50 & -1.44 & 0.82 & -5.02 & -2.76 \\
\hline DNP & 400.9 & 350 & 2.10 & 2.49 & -1.33 & 0.78 & -4.98 & -2.87 \\
\hline
\end{tabular}

a $5 \%$ weight loss, measured by TGA.

${ }^{\mathrm{b}}$ use $\mathrm{o}$-dichlorobenzene as a solvent.

${ }^{\mathrm{c}} \mathrm{E}_{\text {gap }}=$ LUMO-HOMO.

${ }^{\mathrm{d}}$ calculated based on $\lambda_{\text {onset, }} \mathrm{E}_{\text {gap }}=1240 / \lambda_{\text {onset. }}$.

e all potential reported by DPV with ferrocene as internal standard in $o$-dichlorobenzene, LUMO $=-\left(E_{\text {re }}+4.2\right)$, HOMO $=-\left(E_{o x}+4.2\right)$ 